\title{
Европейская пограничная охрана и гибридная война. Взгляд в плане кражи произведений ис- кусства: человеческие измерения и моральные императивы
}

\section{Чарльз Хилл}

\begin{abstract}
Резюме: Кража произведений искусства, в частности, преступления, связанные с античными произведениями искусства, является одним из элементов современного терроризма. Кража и контрабанда художественных работ, в том числе и кража путем разрушения, имели место в древности и продолжаются и в наше время. Борьба с кражами произведений искусства и современная гибридная, многогранная и многомерная война требует новаторства. Существует устойчивый моральный императив, связанный с человеческим измерением, бороться с кражами произведений искусства и ограничивать их худшие последствия путем антитеррористической работы. Идея европейской армии, может быть, будет лучше восприниматься и развиваться, если ее рассматривать как европейскую пограничную охрану, как жандармерию с подготовкой для борьбы с контрабандой произведений искусства и предметов античности, оставив НАТО и далее выполнять свою миссию.
\end{abstract}

Ключевые слова: человеческое измерение, моральный императив, искусство, антиквариат, Сун Цзы, Лиддел Гарт, Хуба Васс де Чезе.

Перед 9/11, когда Мохаммед Атта был студентом в Техническом университете Гамбурга, Атта пытался продавать краденные афганские антикварные предметы, чтобы оплачивать свой курс летной подготовки в Соединенных Штатах. Археолог из Университета Геттингена, к которому он обратился в 1999 году, отклонил его предложение, но этот факт является показатель- 
ным для мышления исламистского фанатика. ${ }^{1}$ Атта не был единственным с таким настроем ума. Древности с Ближнего Востока, из Северной Африки, Центральной и Южной Азии используются в мире исламистского фанатизма как потенциальное средство для зарабатывания денег и для иконоборства.

В течение столетий кража в мире искусства была двух типов, кража или ограбление в конвенциональном смысле и кража путем обмана. В английском законодательстве ${ }^{2}$ «кража - это нечестное присваивание собственности, принадлежащей другому, с намерением навсегда лишить собственника таковой; соответственно толкуются и понятия «вор» и «красть». Кража с обманом включает имитации, подделки и мошенничества всех видов, в том числе кража путем намеренной фальсификации происхождения и неправомерного присваивания. Это категория преступлений в сфере искусства, в которой делают деньги мошенники от искусства. Однако, в последние десятилетия из-за подъема международного терроризма имеет место волна краж другого рода - кражи путем разрушения. (Развитие киберпреступности в будущем может способствовать развитию мошенничества в сфере искусства, а также алгоритмическим кражам.) Что, однако, любопытно, кража предметов искусства часто является ахиллесовой пятой для воров из террористических организаций, из сферы организованной преступности и для неорганизованных преступников.

Кража путем разрушения является сравнительно новым выражением для старой идеи. Она имеет место, когда разрушаются творения искусства и уничтожаются путем разрушения памятники культуры. В последние десятилетия были разрушены бамианские статуи Будды в Афганистане, многие средневековые суффийские гробницы были уничтожены группировкой Ансар ад-Дин (филиал Аль-Каиды) на Тимбукту, Мали, в 2012 году, и важные строения и объекты в Пальмире, Сирия, были разрушены ДАИШ в 2015. Этот позорный перечень продолжается и продолжается религиозными храмами разных вероисповеданий в Пакистане, Ираке и в других местах, взорванными в последние два десятилетия, часто с жестокой гибелью верующих, паломников и туристов около них. Разрушение двух башен Мирового торгового центра в Нью-Йорке 9/11 можно рассматривать как кражу путем разрушения этих примеров архитектурного искусства, каким

1 О попытках Атта торговать древностями рассказано в Heather Pringle, "New Evidence Ties Illegal Antiquities Trade to Terrorism, Violent Crime," National Geographic Magazine 6, no. 13 (June 2014), по состоянию на 23 августа 2016, http://news.nationalgeographic.com/news/2014/06/140613-looting-antiquitiesarchaeology-cambodia-trafficking-culture/, на основе источников из разведывательной службы Германии, Bundesnachrichtendienst.

2 Определение кражи в английском законодательстве можно найти в Section 1 (1), Theft Act 1968. См. J.C. Smith, The Law of Theft, Second Edition (London: Butterworths, 1972), 8ff. Так же, в английском законодательстве вопросы разрушения объектов искусства не очень адекватно рассматриваются в Законе об уголовном ущербе от 1971 года. 
бы не было их значение, как храм Маммона для фанатиков Аль-Каиды, которые их разрушили, или для других, которые любовались линией горизонта Манхэттена.

В западной иудео-христианской цивилизации, в которой есть большие включения средневекового ислама, человеческая и моральная основа борьбы с кражами начинается с концепции служения, сформулированной в Книге бытия, и прямо изложена в одной из Десяти заповедей - «Не укради» (в английской версии Библии короля Джеймса от 1611 года). Концепция служения является моральным императивом, а не относительным моральным вопросом, и простирается в мирском владении, в котором живем мы, в котором жили наши предки и в котором будут жить наши потомки. Это общая для коранических Людей Писания заповедь, для монотеистов иудаизма, христианства и ислама, и мы оказываем взаимное влияние друг на друга и на многих, которые не разделяют нашу религию.

Гибридную или многогранную войну можно найти еще в рассуждениях в Искусстве войны Сунь Цзы, в Непрямом подходе капитана Бэзила Лиддел Гарт и в идеях Рыцаря-джедая капитана Васс. Все эти произведения дают нам понимание того, где мы находимся сегодня, и с ними в этой статье появляется дополнительная перспектива с точки зрения преступлений в сфере искусства. Слово гибридная является удобным сокращением для обозначения многогранной войны. Возможно, многомерная война является более подходящим термином.

Сунь Цзы был китайским воином, который писал о военной стратегии приблизительно две с половиной тысячи лет назад. Из многих переводов Искусства войны на английский наиболее глубоким является перевод Сэмуэля Б. Гриффит с предисловием Б. Х. Лиддел Гарт (Оксфорд, 1963), особенно в части о критически важном использовании информаторов и информации для развертывания разведки в интересах войны. ${ }^{3}$ Альтернативой этому является чтение произведений Клаузевица, соотнося их с нашей эпохой войны с террористами, которая может продолжаться длительное время.

3 Более поздний перевод Искусства войны Сунь Цзы Джона Минфорда (Penguin, 2002) является лаконичным и резким, но как текст хорошо передает силу характера автора и имеет амбицию быть наставлением, более ориентированным на бизнес-менеджеров, чем на военных лидеров. Имеется и издание размером как столик для кофе, изданное обществом „Ин фолио“ в Лондоне (2007). По существу, это перепечатка перевода Роджера Эймса, изданного в серии Ballantine Books издательством Random House в 1993 году, но с предисловием генерала лорда Руперта Смита, который применяет идеи Сунь Цзы в своем командовании силами НАТО, оказывающими помощь Сараево в 1993. Сунь Цзы стоит читать в любом виде, в котором вы найдете его мысли о многомерных и гибридных аспектах войны, и в особенности о сборе информации и превращении ее в разведывательную информацию путем использования агентов. Sun Tzu, The Art of War, translated by Samuel B. Griffiths (Oxford: OUP, 1963), 144-149. 
Капитан Лиддел Гарт был пехотным офицером в британской армии в Первой мировой войне. Ужасы окопной войны побудили его сформулировать свои идеи непрямого подхода, которые он опубликовал в начале Второй мировой войны. Суть его стратегии в том, что армии должны наступать и воевать по линиям наименьшего сопротивления, а их лидеры должны быть новаторами. ${ }^{4}$

Капитан Васс - бригадный генерал Хуба Васс де Чезе (Сухопутные силы США, в отставке) - был командиром роты А, третьего батальона 503-го парашютного пехотного полка, 173-й воздушно-десантной бригады в 196869, развернутой в Бао Лок в Центальном нагорье Вьетнама. Я знаю это потому, что я был $11 \mathrm{~B} 2 \mathrm{P}^{5}$ во взводе «Ноябрь», роты С, третьей роты 503-го полка в то же самое время. Васс был мыслителем-новатором и носил с собой впечатляющий нож Боуи. Моим командиром роты был капитан Гарольд Кроуи, прошедший успешно курс для Зеленых беретов. Оба они были героями для мужчин, которые воевали под их командованием.

Капитан Васс, вместо того, чтобы держаться тропинок в джунглях для поиска врага, который состоял из вьетконговских и северно-вьетнамских формирований, заставлял своих людей двигаться вверх и вниз по ручьям и рекам, по голубим линиям на картах, которые были у нас, и перехватывать врага таким образом. Это была война малых подразделений на уровне отделения и взвода, чтобы приспосабливаться к местности и к противнику и к базовой экипировке, которой мы располагали. Остальные из нас, в других линейных ротах, просекали свой путь через окутанный лианами ад трехэтажного тропического леса с помощью мачете, производя массу шума и, по существу, направляясь в никуда, медленно следуя выдуманными дорожками и контурами, начерченными армейскими картографами. Нет особого смысла чрезмерно жаловаться на сущность и стиль нашей солдатской работы. Просто дела обстояли таким образом.

4 Basil Liddell Hart, The Way to Win Wars: The Indirect Approach (London: Faber and Faber, 1942). Коллеги историки сэра Бэзила имели к нему противоречивое отношение по поводу его поздних публикаций по вопросам стратегии потому, что он после войны беседовал с немецкими генералами и, предположительно, убеждал их утверждать, что они использовали его идеи в своем Блицкриге, термин, которой он придумал для них. Хотя может быть и есть какая-то истина в этом анекдоте, кто знает? Закон Сайера, названный по имени политолога из Колумбийского университета, гласит, что «Академическая политика является наиболее злобной и горькой формой политики, поскольку ставки настолько низкие».

5 11В2Р является обозначением военно-отчетной специальности (ВОС), легкая стрелковая пехота, младший сержант, квалификация парашютиста. Согласно организационно-штатному расписанию и табелю экипировки, сегодня 173-я воздушно-десантная бригадная боевая группа состоит из двух батальонов воздушно-десантной пехоты и большого количества артиллерии, бронированных транспортных средств, вертолетных формирований и служб поддержки. 
После Вьетнама капитан Васс стал одним из новаторов пост-вьетнамской армии США. ${ }^{6}$ Во время первой иракской войны и операции «Пустынная буря» он стал популярен как Рыцарь-джедай, и его идеи гораздо более эффективно интегрировали доктрину воздушно-наземного сражения в стратегию малых войн, что он наблюдал в Центральном нагорье за много лет до этого. Находясь в отставке, он все еще принимает участие в теоретических разработках по гибридной войне в качестве гражданского военного стратега и консультанта при Школе передовых военных исследований при Командно-штабном колледже Сухопутных войск Соединенных Штатов, форт Левенворт. ${ }^{7}$

Капитан Васс был мыслящим в духе Сунь Цзы, вдохновляющим лидером и последователем непрямого подхода Лиддела Гарта. Нынешняя 173я воздушно-десантная бригадная боевая группа, базированная в Винченце, Италия, многим ему обязана за способ своей организации, экипировки и готовности воевать, как и все современные Сухопутные силы США.

Связь между Италией и гибридной войной удивительна, и она продолжает иметь место. В октябре 1969 года из часовни святого Лаврентия в Палермо была украдена известная картина Караваджо Рождество со св. Франциском. Всего через несколько дней была сделана попытка украсть другую сицилийскую картину Караваджо из церкви святого Луки на Кафедральной площади в Сиракузах. В обоих случаях, обоснованно, вина была возложена на мафию, но ее апологеты утверждали, что эти преступления, связанные с искусством, были совершены из-за репрессивных дей-

6 Joe Kubert, Dong Xoai, Vietnam 1965 (New York: DC Comics Library, 2010). Эту книгу называют графическим романом. Капитан Кроуи - это Картер в этой иллюстрированной книге (по неизвестной причине), но его роль в битве и его настоящее имя появляются в приложении, касающегося подразделения А-342.

7 Colonel Huba Wass de Czege, US Army, "How to Change an Army," Military Review LXIV, no. 11 (November 1984): 33-49. По этой основополагающей статье Рыцариджедаи генерала Норманна Шварцкопфа готовились к боям Первой войны в Заливе. Единственный аспект дерзких идей Капитана Васса по реформированию Сухопутных войск США после Вьетнама, который подвергается сомнению этим его почитателем, US 51668287 Hill, это его опора на высоко подготовленных офицеров. Хорошие солдаты, особенно сержанты, ценятся на вес золота в малых войнах: читайте Matti Friedman, Pumpkin Flowers (Chapel Hill: Algonquin Books, 2016), о мотострелковом блокпосте израильских вооруженных сил на одном из холмов в Ливане в 1998 году. Friedman так же написал The Aleppo Codex (Chapel Hill: Algonquin Books, 2013), о страницах одной книги, которые исчезли после того, как она была спасена из Большой синагоги Алеппо в 1947 году. Отсутствующие страницы исчезли в 1950-х, а оставшиеся хранятся в Храме Книги в Иерусалиме. Весь рукописный кодекс был украден франкскими рыцарями при Первом крестоносном походе (в 1099 году, при разграблении Иерусалима), но Саладдин отнял его у них и хранил его в Александрии (где им пользовался Маймонид), пока торговцы из Алеппо не выкупили его у него. Этот кодекс был первой еврейской библией, известной как Корона. Худшей кражей и уничтожением предметов искусства крестоносцев, однако, было разграбление ими Константинополя в 1204 году в начале Четвертого крестоносного похода. 
ствий итальянского государства против нее. ${ }^{8}$ Это бредовое самооправдание, с которым мы должны бороться.

Чтобы подчеркнуть свою позицию, в мае 1993 La Cosa Nostra взорвала заминированную машину перед галереей Уффици во Флоренции, причем погибли шестеро людей и были уничтожены три картины 17-го века. Эти шестеро погибших рассматривались мафией просто как сопутствующие потери в том, что Мафия считала вооруженной борьбой с итальянским государством или, по крайней мере, с частью государства, которую они еще не успели подкупить. Уффици является одним из двух главных художественных музеев Флоренции, который стал объектом нападений из-за своего значения для итальянского общества и для национальной и мировой культуры. 9

В 1974 году банда из ИРА украла несколько картин-шедевров из Рассборо, палладианского особняка в Дублинских горах, графство Уиклоу. ${ }^{10}$ Были похищены работы Вермеера, Рубенса и Гойи. К счастью, у вожака банды была шикарная подружка-дебютантка, Бриджет Роуз Дагдейл. Картины были найдены через несколько месяцев на западе Ирландии в летней даче ее родителей. При расследовании англичанка Роуз сказала, что она и ее соучастники украли картины для того, чтобы добиться перевода двух заключенных членов ИРА из английской тюрьмы в ирландскую. Двое других членов этой банды позже поехали в Колумбию, чтобы консультировать ФАРК насчет использования минометов и взрывчатых веществ. В 1986 году дублинская банда со связями как с ИРА, так и с северными ирландскими протестантами-террористами из Добровольческих сил Ольстера (ДСО), снова напали на Россборо и украли те же картины. ${ }^{11}$ Бандой руководил Мартин Кахилл, известный как Генерал, о котором были сделаны два голливудских гангстерских фильма. К 1993 году все картины, украденные бандой Кахилла, были найдены, за исключением двух небольших пейзажей в стиле каприччио Франческо Гварди, и этот успех был достигнут благодаря разумному использованию информаторов. Мне это известно, поскольку с этими информаторами имел дело я.

В ночь Дня святого Патрика в 1990 году Музей Изабеллы Стюарт Гарднер в Бостоне был ограблен под дулом пистолета двумя мужчинами в

8 Giovanni Falcone, with Marcelle Padovani, Men of Honour: The Truth about the Mafia (London: Fourth Estate, 1992), 161-162. Эта книга была последним завещанием судьи Фальконе перед тем, как он был убит Мафией в мае 1992. Так же, Bill Emmott, Good Italy, Bad Italy: Why Italy Must Conquer Its Demons to Face the Future (New Haven and London: Yale University Press, 2012). Эммот был редактором журнала The Economist и поссорился с Сильвио Берлускони из-за этой книги.

9 Falcone, Men of Honour.

10 Edward Dolnick, The Rescue Artist (New York: HarperCollins, 2005); и в Соединенном Королевстве как Stealing the Scream (Cambridge: Icon Books, 2007).

11 Dolnick, The Rescue Artist / Stealing the Scream, "The General," 56-60. Michael Burleigh, Blood \& Rage: A Cultural History of Terrorism (London: Harper, 2008), 342. 
форме полиции Бостона. ${ }^{12}$ Картины и два других предмета, которые они украли, стоят предположительно полмиллиарда долларов, что в долларовом выражении делает эту кражу самой большой кражей произведений искусств когда-либо. В последующие годы и до нынешнего времени ФБР шло по следам, которые указывают на то, что грабеж был осуществлен итальянскими американцами со связями с Мафией. Информантом высшего уровня ФБР в 1990 году был бостонский ирландец Уитни Булгер, один из братьев которого имел близкие личные связи в высшей иерархии ИРА. Использование информаторов ФБР в данном случае, похоже, было контрпродуктивным. Это когда-нибудь станет учебным примером неэффективной работы с информаторами.

Похоже, двадцать пять лет назад, ФБР пошло по ложному следу. При поиске произведений искусства из музея Гарднер люди из ФБР шли по ошибочному следу: вероятно, в краже принимала участие не связанная с американцами Cosa Nostra, а ИРА периода до Соглашения Cmрастной пятницы. Конечно, возможно, это были другие воры, независимые преступники, не связанные с Мафией или с ИРА, но имеется ряд открытых вопросов о расследовании, проводимом ФБР в течении прошедшей четверти века. Существенным аспектом этого похищения произведений искусства является его подражательский характер, напоминающий преступления Мартина Кахилла. Возможно, на гарднеровское расследование оказали влияние неправильные люди. В 1994 году Кахилл был казнен ИРА за его связи с протестантскими террористами из ДСО.

Опять же в 1994 году, в начале зимних Олимпийских игр, проводимых в Лиллехаммере, Норвегия, из Национальной галереи в Осло был похищена оригинальная версия Крика Эдварда Мунка. И снова, в 2004, но из Музея Мунка была украдена другая версия Крика. В 1994 году ворами были местные отморозки, но в 2004 это в основном были косовские албанцы, проживающие в Гетеборге, Швеция, которые совершили вооруженное ограбление наличности инкассаторской машины NOKAS в Ставангере, Норвегия, за несколько месяцев до этого, одетые в камуфляжах и с автоматами. Они убили офицера местной полиции. Это вооруженное ограбление второй версии Крика было организовано в качестве отвлекающего маневра. Вместе с коллегами из Осло и Лондона я был сотрудником под прикрытием в расследовании в 1994 году, но как полицейский в отставке, в 2004 году моя деятельность и мой интерес к этому второму преступлению были отвергнуты, когда я указал на многонациональный характер людей, участвующих в преступлении. Однако, полиция Осло нашла вторую версию Крика через два года в 2006, пообещав награду в миллион конфеток М\&M одному из организаторов преступления, шокохолику албанского происхождения Дэвиду Тоска. Информаторы являются ключом к разрешению преступлений, связанных с произведениями искусства, и чем шире меж-

12 Ulrich Boser, The Gardner Heist (New York: HarperCollins, 2008), $113 \mathrm{ff}$. 
дународные связи информаторов, тем более полезными могут они оказаться. Конечно, они могут оказаться лжецами, которые работают на себя.

За несколько месяцев до 9/11 талибами были разрушены гигантские статуи Будды в Бамиане, удаленной области Центрального Афганистана. Эти статуи были там в течение восемнадцати столетий. ${ }^{13}$ Хотя в Коране нет требования уничтожать изображения, подобные этим гигантским каменным буддам, есть несколько религиозных текстов (хадисы) из древнего ислама, которые на самом деле запрещают изображения в искусстве. Поэтому фанатики ислама подобны фанатикам шестнадцатого и семнадцатого века протестантской реформации, которые уничтожали изображения, созданные средневековым католическим христианством, или иконоборцам греческой православной церкви в восьмом и девятом веках. Секуляристские Французская и Русская революции были разрушительными и иконоборческими. Историческая перспектива помогает отделить причуды краж от идеологического и теологического сумасшествия.

Американская Война за независимость не была ни разрушительной, ни иконоборческой. Значение этого факта было резюмировано сто шестьдесят лет после американской революции генералом Эйзенхауэром в Метрополитен-музее искусств 2 апреля 1946 года: «... я наверняка знаю, что за демократией всегда стояли, по крайней мере, вне материализма и разрушительности войны, те идеалы, за которые она воюет». Далее он продолжил говорить о послевоенном возрождении внимания к культурным ценностям. $^{14}$

13 K. Warikoo, ed., Bamiyan: Challenge to World Heritage (New Delhi: Third Eye, 2002), xi and 14; см. еще Rohan Gunaratna and Khuram Iqbal, Pakistan: Terrorism Ground Zero (London: Reaktion Books, 2011). Смотри на стр. 91 список объектов нападения. Стоить сравнить ментальность Талибана/Аль-Каиды/ДАИШ с ментальностью фанатиков протестантской Реформации в Eamon Duffy, The Stripping of the Altars: Traditional Religion in England 1400-1580 (New Haven and London: Yale University Press, 2002); Noah Charney, ed., Art Crime: Terrorists, Tomb Raiders, Forgers and Thieves (New York and Basingstoke: Palgrave Macmillan, 2016), включающую Matthew Bogdanos, "Thieves of Baghdad: And the Terrorists They Finance," 118131. Эта глава адаптирована из книги полковника Bogdanos, Thieves of Baghdad (New York and London: Bloomsbury, 2005). Jason Burke, The New Threat from Islamic Militancy (London: The Bodley Head, 2015), смотри стр. 44-45 о ваххабитском культе разрушения и Alan Besancon, The Forbidden Image: An Intellectual History of Iconoclasm, в переводе Jane Marie Todd (Chicago and London: University of Chicago Press, 2000), 78-79. The Art Newspaper online, 27 September 2016, o приговоре аль-Мадхи.

Один фотограф из Национальных архивов США за год до речи генерала Эйзенхауэра в Метрополитен-музее (12 апреля 1945) показал Эйзенхауэра в соляной шахте Меркерс, недалеко от гор Харц, в военной форме класса А (фуражка, галстук и перетянутый поясом тренчкот) вместе с генералом Брадли и генералом Паттоном в касках и боевой форме оливкового цвета, смотрящими на награбленные нацистами у миллионов уничтоженных евреев предметов. Сравните эту фотографию с наличными архивными фотографиями фельдмаршала Германа Геринга, рассматривающего свою награбленную коллекцию предметов искус- 
Интересно отметить, что когда банды Аль-Каиды (известные как Ансар ад-Дин) вышли из пустыни Сахара и атаковали Тимбукту, Мали, были одержимы идеей разрушать мусульманские гробницы средневековых святых суфий и исламские библиотеки, которые создавались в течение половины тысячелетия. Недавно, в Международном суде в Гааге, лидер АльКаиды в Тимбукту, Ахмад аль-Факи ас-Мади, обратился к судьям с признанием, что он увидел свет и сожалеет о своем иконоборчестве. Суд признал его вину и приговорил его к девяти годам заключения. Стоило бы узнать, какие выводы сделали для себя из его раскаяния и его приговора его друзья-иконоборцы из Аль-Каиды и ДАИШ.

В 2015/2016 ДАИШ пытались разрушить древние памятники Пальмиры, но были вынуждены отступить в сторону Ракки на Эвфрате, недалеко от Ирака. В августе 2016 года, чтобы отметить свою победу над ДАИШ, русские привезли симфонический оркестр в Пальмиру, там, где за несколько месяцев до этого ДАИШ замучили, обезглавили и распяли Халеда аль-Асаада, 83-летнего археолога и смотрителя древнего города. Генеральный директор сирийских памятников культуры из Дамаска на международном саммите культуры в Эдинбурге сказал, что три четверти похищенных древностей, задержанных в операциях по борьбе с контрабандой, оказались фальсификатами. В их число входят фальшивые древние Библии и Кораны. ${ }^{15}$ Надо помнить, что кража путем обмана все же является кражей.

Гибридная, многогранная, многомерная война требует учета культурных и анти-культурных элементов конфликта, о чем и говорил прямо генерал Эйзенхауэр после Второй мировой войны, и что имели в виду русские с их симфоническом оркестром в Пальмире в середине лета 2016 года. Кража предметов искусства путем разрушения, как и все кражи предметов искусства, являются частью более широкого мира войны.

Что делать? ${ }^{16}$ Эти старые слова Ленина, переведенные на английский, предполагают, что-то надо делать, и как Айк предположил в 1946 году, дела можно делать так, чтобы был положительный результат. План Маршалла помог добиться этого. Сегодня это означает новаторство, интегрированное с нашими ресурсами, возможно лучшим образом через применение непрямого подхода к проблемам кражи предметов искусства исламистскими фанатиками. Сунь Цзы, капитан Бэзил Лиддел Гарт и бригадный генерал Хуба Васс де Чезе дают нам такой интеллектуальный подход.

ства. В год после речи Айка в Метрополитен-музее (General Dwight D. Eisenhower, "Art in Peace and War," in The Metropolitan Museum of Art Bulletin (New Series) 4, no. 9 (May, 1946), 221-223), в мае 1947, в обращении к выпускникам Гарвардского университета генерал Маршалл раскрыл свой план восстановить западноевропейскую цивилизацию. Сейчас нам нужно ее хранить и помогать другим восстанавливать свою.

15 Tim Cornwell, "Three-quarters of seized artefacts are fakes, says Syrian official," The Art Newspaper, no. 282 (September 2016), 5.

16 Vladimir I. Lenin, "What is to be done," Iskra, no. 4 (May 1901); и в мягкой обложке (London: CreateSpace, 2014), стр. 196 о ленинизме. 
Для начала мы должны усовершенствовать свою полицейскую работу, особенно на границах (включая порты и аэродромы). В военизированном полицейском контексте, в котором объекты транспортируются через границы, и эти объекты находятся в руках либо воров ценностей искусства и бесчестных посредников, или перевозятся их подставными лицами.

На краденые произведения искусства и похищенные античные предметы следует обращать больше внимания в смысле пресечения, проведения обысков, задержаний и арестов, когда это необходимо. Обстоятельная разумная беседа с задержанными и обыскиваемыми лицами очень важна.

Во-вторых, надо ужесточить в международном, и главное в национальном, плане законодательство, направленное против краж. Органам охраны правопорядка следует дать указание рассматривать значение преступлений, связанных с искусством, как потенциальную ахиллесову пяту преступных организаций, как при операциях против террористов, так и против квази-гангстерских государственных операциях. Военные подразделения в зонах конфликтов могут содействовать военизированным пограничным силам для достижения этой цели.

В-третьих, можно и нужно поощрять более эффективное использование живых информаторов сотрудниками органов охраны правопорядка. Во всех описанных выше случаях нахождения украденных произведений искусства операции основывались на использовании информаторов. Информаторы не проводят операцию, но они обеспечивают критически важную информацию. Лучшая подготовка для использования и менеджмента информаторов является ключом к успешному нахождению краденых произведений искусства и похищенных античных предметов. Так же, недостаточно используемым видом сбора информации является нахождение информации в открытых источниках, или в Интернете, не требующим разрешения на перехват коммуникаций. Развитие электронного подслушивания может подтверждать то, что дают агентурные источники информации, обеспечивать связь с другими и определять их местонахождения.

Недавнюю светлую идею Комиссии ЕС об Европейской армии (201516) ${ }^{17}$ можно было более эффективно переформулировать как эффективную военизированную пограничную охрану при правильной подготовке и организации. Действительно, надо бы проконсультироваться с бригадным генералом в отставке Васс де Чезе (когда-то он был штабным офицером в ставке НАТО в Брюсселе). Он наверняка знает, как это сделать. Его ключом к успешным инновациям является интеграция. Комиссии ЕС лучше бы сделать ставку на дополнение НАТО, чем пытаться организовать параллельную вселенную.

17 Andrew Sparrow, "Jean-Claude Juncker calls for EU Army," The Guardian online, March 8, 2015 (чтобы сохранить лицо перед Россией), по состоянию на 7 марта 2016, https://www.theguardian.com/world/2015/mar/08/jean-claude-juncker-callsfor-eu-army-european-commission-miltary. 
То, что называли повышением уровня осознанности, является интегральной частью образования и оказания помощи борьбе против преступлений, связанных с искусством; против ограблений, краж и мошенничеств во всех их обличиях. Хотя украденные предметы искусства в военное время и в малых войнах против террористов не являются центральной проблемой для Войны против террора, они представляют собой значительный периферийный вопрос, который может помочь демократическим обществам упорядочить свои приоритеты во время этой борьбы и после ее окончания. В конце концов, во имя чего мы воюем, если не во имя цивилизованного общества для нас и будущих поколений, и чтобы избежать прошлых катастроф человеческих цивилизаций?

Кеннет Кларк был выдающимся эстетом конца двадцатого века, который создал книгу и телевизионный сериал, названные Цивилизацией. В них он писал и говорил перед камерой, что «... порядок лучше, чем хаос, создание лучше, чем разрушение. Я предпочитаю мягкость насилию, прощение вендетте. В целом, я думаю, знание предпочтительнее невежества, и я уверен, что сочувствие к людям более ценно, чем идеология. Я верю, что несмотря на последние успехи науки, люди не изменились сильно за последние два тысячелетия; и следовательно, мы должны пытаться научиться чему-нибудь у истории. История - это мы». И тогда он добавил: «Прежде всего, я верю в данный богом гений определенных личностей и я ценю общество, которое делает их существование возможным». ${ }^{18}$ (Под определенными личностями он имел в виду великих художников древности, вчерашнего и сегодняшнего дня.)

Для того, чтобы достичь этого, нам нужно работать над новаторскими идеями и непрямыми подходами. Сохранение великих произведений искусства древности для нашего настоящего и для нашего будущего требует этого.

18 Kenneth Clark, Civilisation (London: John Murray, 2005) (first published by the BBC in 1969), 245-246. Одно предостережение для времени, когда мы выиграем Войну с террором в Alistair Horne, Hubris: The Tragedy of War in the Twentieth Century (London, Weidenfeld \& Nicolson, 2015). 


\section{6 авторе}

Чарльз Хилл служил два года в Сухопутных силах США. Поступив добровольцем в Призыв в 1967 году, он прошел начальную, пехотную и парашютную подготовку. По возвращение из Вьетнама он получил степень бакалавра по истории в Университете имени Джорджа Вашингтона (Вашингтон, округ Колумбия) и стал фульбрайтовским стипендиантом Тринити колледжа в Дублине. Уйдя в отставку как главный инспектор уголовного расследования в столичной полиции (Новый Скотланд Ярд) в Лондоне в 1997 году, сейчас он занимается нахождением украденных и разграбленных произведений искусства по всему миру. E-mail: hillartrisk@aol.com. 